1904. In good health March 13th, 1905. Letter from medical attendant

CASE 70.-An unmarried woman, aged 33 years, Fibroids, monorrhagia, pain; May 30th, 1904 . Convalescence slow but satisfactory. Letter from patient, March 29th, 1905.

CASE 71.-An unmarried woman, aged 47 years. Fibroids; painful micturition ; total hysterectomy, May 30th, 1904. " Health greatly improved since the operation." Letter, March 3rd, 1905

CASE 72.-An unmarried woman, aged 60 years. Fibroid impacted in the pelvis; retention of urine; June 27th, 1904 . The patient was much more comfortable since the operation. Her general health is not good. Letter, March, 3rd, 1905.

C $\triangle$ SE 73.-A married woman, aged 48 years. Fibroids; profuse chos 1905 , in good health.

CASE 74.-A married woman, aged 48 years. Fibroids; menorrhagia July 4th, 1904. The patient was reported well, Feb. 28th, 1905, by her medical attendant.

CASE 75. - A married woman, aged 38 years. Fibrosis ; metrorrhagia July 11th 1904. "The patient is much better." Letter March 3rd,

CASE 76.-An unmarried woman, aged 40 years. Fibroids, pain, and frequent micturition": July 11th, 1904 " "General health fairly good." Letter, March, 1905

CASE 77.-An unmarried woman, aged 33 years. Fibroids ; menorrhagia; July 11th, 1904. Convalescence slow. Letter, March 9th, 1905. CASE 78. - An unmarried woman, aged 27 years. Fibroids, tumour thought to be a solid ovarian before operation, July 26th, 1904 (Middlesex Hospital). "I have been very much better in health since my operation." Letter from patient March 13th, 1905.

CASE 79.-An unmarried woman, aged 50 years. Septic uterus and hydrosalpinx; August 17th, 1904 (Middlesex Hospital). Personal visit in February, 1905. In good health.

CASE 80.-An unmarried woman, aged 51 years. Fibroids; profuse menorrhagia; August 24th, 1904 (Middlesex Hospital). The patient was very well March 2 nd, 1905. Letter from medical attendant.

CASE 81.-A married woman, aged 39 years. Fibrosis ; profuse menorrhagia; Sept. 12th, 1904. Reported to be in good health two months after leaving hospital.

CASE 82.-A married woman, aged 39 years. Fibrosis ; menorrhagia; a chronic invalid ; total hysterectomy, Sept. 26th, 1904. Convalescence slow but satisfactorv. Letter March 29th, 1905.

CASE 83.-An unmarried woman, aged 40 years. Fibroids; metrorrhagia ; Sept. 28th, 1904. (Middlesex Hospital.) The patient (a nurse in a county asylum) says she feels better than she has done for years. Letter, March 28th, 1905.

CASE 84.-A married woman, aged 40 years. Fibroids; metrorrhagia total hysterectomy, Oct. 3rd, 1904. No report since leaving the hospital.

CASE 85.-A married woman, aged 48 years. Fibroids; septic ; continuous metrorrhagia; total hysterectomy, Oct. 3rd, 1904. " Her health has improved wonderfully since the operation." The patient left for

CASE 86.-A married woman, aged 34 vears. Fibroids; Oct. 3rd, 1904.

Very good report from the patient. Letter March, 1905 .

CASE 87.-A married wornan, aged 40 years. Cervix fibroid; tightly impacted and degenerated; Oct. 7th, 1904. The patient had done extraordinarily well ; can do a hard day's work. Letter from medical attendant, March 31 st, 1905

CASE 88.-A married woman, aged 46 years. Fibroicts; three of very large size and one impacted in the pelvis; Nov. 14th, 1904. "My
wife is better now than she has been for years." Letter, March 6th, CASE 89. - A married woman, aged 33 years. Fibrosis; persistent bleeding; Nov. 14th, 1904. Good report from the patient; March 31st 1905.

OASE 90.-A married woman, aged 37 years. Fibroids; menorrhagia marked anæmia; Nov. 2lst, 1904. "My health is better than I have ever had it." Letter from patient, March 3rd, 1905.

CASE 91.-A married woman, aged 69 years. Fibroids; dangerous bleeding; diabet es; sugar ten grains to the ounce; cancer of the body of the uterus: Nov 28th 1904 Her medical attendant writes, April 4th, 1905, that the patient " is wonderfully well."

CASE 92 - A married woman aged 30 vears. Fibroids ; profuse (1904. The patient profuse excellent convalescence.

CASE 93 - An unmarried woman, aged 52 years. Fibroids; pain and CASE 93.- An unmarried woman, aged 52 years. Fibroids ; pain and menor

Oa in a county asvlum and is very 37 . Leater, March 28 , 1905.

bilateral salpingitis ; total hysterectomy, Dec. 5th, 1904 . No report ilateral salpingitis ; total

OASE 95.-A married woman, aged 44 years. Fibroids, small but numerous; protuse metrorrhagia; distended Fallopian tubes ; total numerous; profuse metrorrhagia ; distended Fallopian tubes ; total hysterectomy, Dec. 12th, 1904. The patient has done ext

well. Letter from her medical attendant March 31st, 1905 . CASE 96.-An unmarried woman, aged 48 years. Fibroids ; pain and
frequent micturition; Dec. 19th, 1904. Good report from the patient Feb. 15th, 1905

CASE 97.-A married woman, aged 35 vears. Fibroids ; menorrhagia; profound anamia; Dec. 19th, 1904. Good report from the patient, March 10th, 1905

CASE 98.-A married woman, aged 41 years. Fibroids; menorrhagia ; anæmia; Dec. 19th, 1904. Letter from patient, Feb. 3rd, 1905. "Getting quite strong again."

CASE 99. -An unmarried woman, aged 40 years. Fibroids; hæmorrhage and anæmia ; Dec. 20th, 1904. Good report from the patient.

CASE 100.-An unmarried woman, aged 52 years. Fibroids; hæmorrhage ; Dec. 20th, 1904. "Much stronger and doing well." Letter from patient Feb. 3rd, 1905, and March 20th, 1905

In addition to the 81 patients from whom the uterus was removed for fibroids and diffuse adenomyoma there were eight women in whom myomectomy or enucleation was performed, and one woman, aged 28 years, from whom a large soft fibroid weighing 14 pounds was removed from the round ligament of the uterus. 'This tumour grew into the abdomen like a subserous stalked fibroid. Each of these patients made an uninterrupted recovery. Myomectomy and enucleation are justifiable procedures in women contemplating marriage and in married women so anxious for offspring that they are willing to run serious risks on the chance of obtaining living children. Experience, however, teaches this stern lesson: after the enucleation of a fibroid in the procreative period of life a woman is 20 times more likely to grow more fibroids in her womb than to conceive successfully.

Brook-street, W.

\section{ON PNEUMOCOCCAL SORE-THROAT WITH NOTES OF A FATAL CASE.}

BY W. PASTEUR, M.D. LoND., F.R.C.P. LOND.,

PHYSICIAN TO THE MIDDLESEX HOSPITAL; CONSULTING PHYSICIAN TO THE NORTH-EASTERN HOSPITAL FOR CHILDREN.

AMONG the acute inflammations of the faucial region there is one, pneumococcal angina, which has not apparently as yet received in this country the attention it deserves. At a recent public examination not a single candidate even mentioned this condition in discussing the differential diagnosis of diphtheria. Pneumococcal inflammations of the fauces and larynx are, however, well worthy of attention on account of the close clinical resemblance they may present to other acute inflammations of those regions, especially diphtheria.

The occurrence of inflammatory lesions of various mucous membranes, with or without membranous exudation, in association with pneumonia and broncho-pneumonia has been recognised for many years. A very remarkable case of this kind is recorded by Cary and Lyon. ${ }^{1}$ But examples of primary inflammation of the faucial region are much more uncommon. Jaccoud, ${ }^{2}$ T. K. Monro, ${ }^{3}$ and others have placed on record cases of membranous sore-throat of pneumococcal origin which clinically were very like diphtheria. The appearances in the case I am about to relate differ widely from these and afford a good example of another variety of pneumococcal pharyngitis, the "angine érythémateuse pneumococcique" of French authors.

Referring to the probable frequency of acute membranous tonsillitis and pharyngitis of pneumococcal origin, Foulerton ${ }^{4}$ remarks that "the exact bacteriological identification in these cases is rendered difficult by the fact that the organism is a frequent parasite of the healthy mouth. But the number of cases in which there are the formation of a false membrane and destruction of the superficial layer of the epithelial membrane associated with the presence of the coccus in predominant numbers and without any of the other bacteria -B. diphtheriæ, streptococcus pyogenes, and saccharomyces albicans-which are known to cause similar lesions, leaves little doubt as to the fairly frequent occurrence of an acute membranous pharyngitis due to this cause."

A healthy, well-nourished boy, aged three and a half years, was seized with sudden illness on Oct. 24th, 1903. The prominent symptoms were sore-throat with great pain on deglutition and high fever, which had persisted. There was no initial vomiting nor had there been any signs of laryngea implication or of pulmonary trouble. He had only taken small quantities of milk with much difficulty. He was admitted to the Middlesex Hospital on the fourth day of illness in the following condition. The face was pale with a dusky malar flush. The respirations (40 per minute) were not laboured. The pulse (120) was soft, full, and regular. The glands at the angle of the jaw were moderately swollen on both sides and very tender. The skin was dry and hot (temperature, $103^{\circ} \mathrm{F}$.). There were no signs of desquamation and no puffiness. There was no discharge from the nose or ears. A careful examination of the heart and lungs revealed no abnormal signs. A specimen of urine passed soon after admission gave a positive result to Ehrlich's diazo reaction it was free from albumin. The uvula, soft palate, and faucial pillars on both sides were slightly cedematous and intensely red and glazed. Both tonsils were somewhat swollen and intensely injected. There were no exudation of any kind and

1 American Journal of the Merical Sciences, September, 1901 2 Semaine Médicale, July, 1893

3 Glasgow Medical Journal, vol, 1 vi. 274.

4 Transactions of the Pathological Society of London, vol. liii., p. 293. 
no plugging of the follicles of the tonsils. The posterior wall of the pbarynx could not be seen. The tongue was rather thickly furred and the breath was very offensive.

Progress of case. -6000 normal units of diphtheria antitoxin were injected on admission and a swab was taken from the throat for bacteriological examination. The temperature ranged high throughout the illness, exceeding $103^{\circ}$ every day and only once falling as low as 101\%. On Nov. 7th the appearance of the throat was much the same. There were no signs of exudation. The patient had great difficulty in swallowing and frequent regurgitation of fluid through the nose. The enlarged spleen could be felt below the ribs but it was not tender. The swab cultures yielded an abundance of micrococci but no bacilli were present. Widal's reaction gave a negative result. No signs of bronchopneumonia were present. There were considerable enlargement and much tenderness of the glands at the angles of the jaw. On the 10th, attempts to feed through a nasal tube failed; nutrient enemata of milk and beef tea had been given since the $8 \mathrm{th}$. On the 11 th there were signs of cerebral irritation. The child was curled up to one side with the wrists flexed and the knees bent up. He strongly resented all interference, cried out at sudden noises, and had definite photophobia. No paralytic symptoms were observed. During the last two days the foetor of the breath had increased and become distinctly gangrenous. On the 9 th the throat was still intensely red and glistening, but to-day (11th) the whole of the uvula and the adjacent portions of the soft palate were brown and sloughing. There were no signs of peeling and the urine remained free from albumin. The nutrient enemata were omitted on account of rectal intolerance. On the 14th the temperature had been more remittent since the 11 th and the patient was growing rapidly weaker. The throat was sprayed frequently with chlorine water but without appreciable effect on the fœtor and unsuccessful attempts had been made to irrigate the naso-pharynx with antiseptics. There was now a grey gangrenous slough involving the uvula and the palatal arches. The respirations had risen from 30 to over 70 per minute and signs of broncho-pneumonia had made their appearance in the left lung, both in the upper and lower lobes. Death took place on Nov. 15th, the twenty-second day of illness. There was slight diarrhœea during the last three days. There was no nasal discharge at any time.

Necropsy.-A post-mortem examination was made 31 hours after death, the weather being cold. The body was emaciated and somewhat rachitic. No beading of ribs could be seen. There was some excoriation at the right angle of the mouth. The whole of the soft palate, both pillars of the fauces, and the tonsils formed a large greenish gangrenous mass. The glotto-epiglottic fold and pyriform sinuses were also discoloured and bathed by a thin greenish purulent discharge. The sloughing area reached as far forwards as the hard palate. The glands at the angle of the jaw and those of the posterior triangles were much enlarged. The right pleura contained two and a half ounces of thin reddish pus. On the posterior aspect of the left pleura, just on a level with the bifurcation of the trachea, was a circular patch of softening. The cesophageal, bronchial, and mediastinal glands were enlarged. The bronchi were congested and contained some thick purulent exudation. The upper lobe of the left lung was congested. There was one small gangrenous patch on the posterior aspect. The lower lobe was riddled with patches of broncho-pneumonia which were becoming gangrenous. The largest gangrenous cavity was of the size of a hazel nut. There were similar changes in the right lung. A gangrenous patch of the size of a walnut was in the upper lobe and there were areas of collapse in the lower lobe The heart was natural. The stomach was contracted and healthy. The œesophagus was healthy. The kidneys were somewhat enlarged and cloudy. There were cloudy swelling and much post-mortem discolouration in the liver. The spleen was enlarged and congested. As regards the head, the scalp, calvaria, and sinuses were natural. There were slight congestion of the pia-arachnoid and some excess of cerebro-spinal fluid. No meningitis was present. The brain substance was natural.

Bacteriology.-Cultures obtained post mortem from the pharynx and lungs were examined by Mr. A. G. R. Foulerton, who informed me that the diplococcus pneumoniæ was present in predominating numbers, together with a bacillus (probably the result of post-mortem infection) in smaller quantity. The diplococcus was tested on a mouse and found to be of normal pathogenicity for that animal.
The difficulties surrounding the clinical diagnosis in this case were very great. The child was too young and too desperately ill to permit of any really satisfactory examination of the naso-pharynx being made. Diphtheria antitoxin was injected as a precautionary measure only, for the sudden onset, severe initial symptoms, and persistent high temperature did not lend support to this view of the case. The absence of all exudation on the tonsils and fauces and the total absence of any signs of desquamation excluded the diagnosis of scarlet fever. On the whole, the appearance of the fauces and soft palate on admission more nearly resembled erysipelas than anything else but the very moderate degree of œdema militated strongly against this view. The possibility of a pneumococcal inflammation of the pharynx was carefully considered but could hardly be maintained in the face of the negative result of the first bacteriological examination. I am satisfied that the pharynz was the site of primary infection. 'The lungs were repeatedly examined and no signs of broncho-pneumonia or other lesion detected until the later stages of the illness when gangrene of the palate was already well marked.

The occurrence of gangrene in pneumococcal inflammations of mucous membranes is well established. Munro's patient recovered with a perforation of the faucial pillars and I may fitly refer here to a remarkable case which came under my notice some time ago and was placed on record by Foulerton. ${ }^{5}$ The patient, aged 26 years, had suffered from a "quinsy" a fortnight before admission to the Middlesex Hospital and had been ill ever since. He died from pyæmia three days after admission. The necropsy revealed an almost universal pneumococcic gastritis, with extensive necrosis of the glandular layer of the mucous membrane of the stomach. There was a deepish ragged ulcer in the right tonsil. It seems probable that in this case the primary lesion was a pneumococcic infection of the right tonsil, though this was not proved bacteriologically.

I am indebted to my colleague, Dr. J. Kingston Fowler, for permission to mention a case of membranous laryngitis arising in connexion with an acute pneumococcal inflammation of the lungs. The patient, a man, aged 38 years, was admitted in the fourth week of an acute illness with signs of consolidation in the left lung. He lived for 34 days after admission, during which period the greater part of both lungs became consolidated. The necropsy revealed a very extensive pneumonia of both lungs with a small smoothwalled gangrenous cavity at the posterior apex of the left lower lobe. There was a patch of toughish adherent membrane on one of the vocal cords from which Mr. Foulerton obtained a pure culture of diplococcus pneumoniæ. This organism was also present in preponderating numbers in the cultures obtained from scrapings of the lung tissue just outside the cavity in the left lung. The patient had not presented any laryngeal symptoms.

A striking example of pneumococcal laryngitis has been recorded by Seuvre. ${ }^{6}$ The case is that of a boy, aged eight years, in whom symptoms of laryngeal obstruction supervened in the course of an attack of "grippe." Tracheotomy had to be performed and pneumococcus in pure culture was obtained from pieces of membrane coughed up through the tracheotomy tube. It is clear from a consideration of recorded cases that pncumococcal pharyngitis may present different clinical forms. French observers who have paid some attention to the subject describe the following varieties : ${ }^{7}$ (1) the suppurative; (2) the pseudo-membranous; (3) the follicular; (4) the inflammatory or erythematous; and (5) the herpetic.

The erythematous form was first described by Rendu and Boulloche. $^{8}$ The appearance of the fauces described by these observers agrees very closely indeed with that presented by my patient in the earliex stages of his illness. The etiology of their case was interesting. The patient, a nurse in a children's hospital, slept in a dormitory from which during the wcek preceding her illness three other nurses had been warded with acute pneumonia. Her illness developed very acutely with chills, intense headache, and high fever and subsided by crisis with profuse sweating and diuresis after a duration of only 36 hours. 'There were no pulmonary symptoms.

An altogether similar case is recorded by Gaultier ${ }^{9}$ in a 5 Loc. cit.
6 Quoted by Cary and Lyon, loc. cit.

7 Consult E. Gaultier, Thèse de Paris, 1896, and Sophie Weinberg, Thèse de Paris, 1895

$\checkmark$ Bulletin de la Société Médicale des Hôpitaux, May, 1891. 9 Loc. cit. 
young man. Crisis occurred on the fourth day after an acute onset with rigor. There was a short relapse with recurrence of pharyngeal inflammation after an afebrile interval of six days. A fatal termination in pneumococcal pharyngitis is quite exceptional if one may judge by the recorded cases, and the occurrence of gangrene, which determined the bronchopneumonia in my patient, is also rare. Monro's patient furnishes the only other instance of this that $I$ have come across.

The local signs of pneumococcal pharyngitis are in no sense distinctive. The membranous form may closely simulate diphtheria and a bacteriological examination alone reveal the true nature of the case. Somewhat similar appearances are also met with in some cases of streptococcal inflammation of the throat ${ }^{10}$ but here the exudate is usually thinner and looser in texture and less adherent than in pneumococcal or diphtheritic inflammations. More reliance may be placed, in my opinion, on the early symptoms and mode of onset. In pneumococcal sore-throat the onset is usually quite sudden, of ten with rigor or chills, the initial symptoms are severe, and the temperature rises rapidly to $103^{\circ}$ or higher-a grouping of symptoms strikingly like those of pneumonia and very rarely met with in anything like the same degree in diphtberia or even in streptococcal pharyngitis. The disease tends to run a short course-from two to five days-but to this there are exceptions. The erythematous form of the affection is most likely to be mistaken for scarlatinal angina and here the diagnosis-apart from bacteriological findings-must rest mainly on the absence of other signs of scarlet fever. It is worthy of note that a considerable number of the recorded cases of pneumococcal sore-throat have been in adults.

Chandos-street, $W$.

ON THE

RESEMBLANCES EXISTING BETWEEN THE "PLIMMER'S BODIES" OF MALIGNANT GROWTHS AND CERTAIN NORMAL CONSTITUENTS OF REPRODUCTIVE CELLS OF ANIMALS.

BY J. BRETLAND FARMER, F.R.S.;

$$
\begin{aligned}
& \text { J. E. S. MOORE; } \\
& \text { AND } \\
& \text { C. E. WALKER. }
\end{aligned}
$$

IT is proposed in the present communication to present the results of investigations bearing on the nature of those remarkable structures known as "Plimmer's bodies." 2 As is well known, these are found in many cancerous growths and are most commonly encountered in the younger or growing regions of the tumour. They appear in the form of vesicles and they consist essentially of a fairly welldefined wall containing a clear space in which is suspended
FICr. 1.

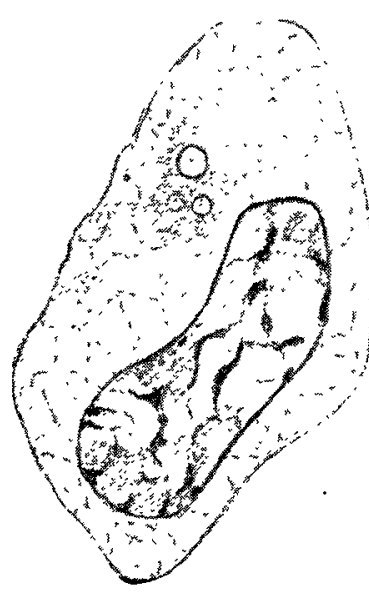

Frample of "Plimmer's bodies" from scirrhus of the breast: an archoplasm. three small "bodies" in an
FIG. 2.

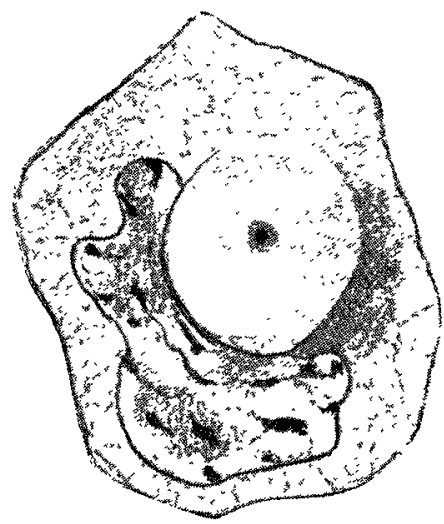

Later stage in the development of the "bodies."
10 Weinberg: loc. cit.

1 A paper read before the Royal Society on May 11th, 1905 2 Plimmer: Practitioner, vol. Ixii. a small darkly staining granule (Figs. 1 and 2). They are most commonly to be met with in tumours of a glandular or glandular-epithelial origin. ${ }^{3}$ They lie in the cytoplasm of the cancer cell and usually in close proximity to the nucleus. In size they vary from excessive minuteness to that of the nucleus itself.

The special interest attaching to them depends on the fact that they have commonly been regarded as peculiar to cancerous cells, although Honda ${ }^{4}$ believes that he has occasionally also encountered them in inflammatory tissues. They have been variously interpreted. Some investigators have regarded them as parasitic organisms, more or less intimately connected with the etiology of the disease, whilst others have seen in them a differentiation of the cytoplasm of the cancerous cell itself. It has been suggested also that they might be derived from the centrosomes within the archoplasm, ${ }^{5}$ but the observations of Benda ${ }^{8}$ that centrosomes coexisted independently of them in the cell has rightly been held to disprove this hypothesis.

Our own investigations indicate, however, that there are good grounds for reconsidering the whole position and a comparison of the processes that normally obtain during the final stages of development of the reproductive elements in man and the other mammalia appears to us strongly to suggest that a parallel between the Plimmer bodies of cancer and certain vesicular structures occurring regularly in the gametogenic, but not in the ordinary somatic, cells may be found to hold good.

It was shown by one of us ${ }^{\tau}$ in 1895 that during the prophase of the heterotype (first maiotic) mitosis of the spermatogenetic cells the archoplasm undergoes a highly characteristic and peculiar metamorphosis. In normal somatic, or premaiotic, cells the archoplasm is seen to lie beside the nucleus as a dusky mass of protoplasm in which are contained the centrosomes. That is, the attraction sphere consists of the archoplasm plus the centrosomes. But during the prophase of the heterotype mitosis these constituents become separated. The centrosomes are found to lie outside of, and detached from, the archoplasm. At the same time the archoplasm itself undergoes a change. It becomes vesiculated and finally, at the close of this cell generation, it is lost in the general cytoplasm of the daughter cells.

In the prophase of the second maiotic division (homotype) the same phenomena recur. When the homotype mitosis is over the constituents of the sphere, or at least some of them, enter into direct relation with parts of the spermatozoon which arises by further differentiation of the cell. As regards the archoplasm, with which we are more directly concerned, it is again seen to contain a number of minute vesicles which continue as before to grow in size, whilst each contains a single refractive and stainable granule (Fig. 3). Subsequently several of these vesicles fuse
FrG. 3.

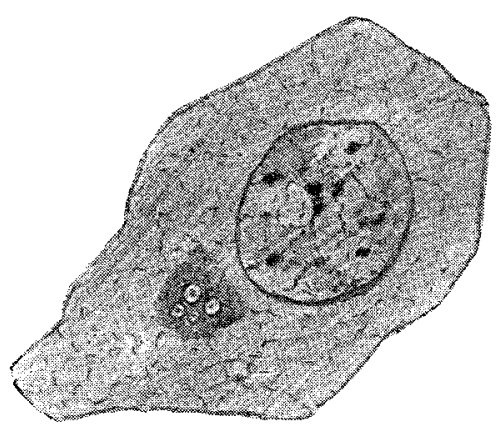

Spermatid of mouse (early stage).
FIG. 4.

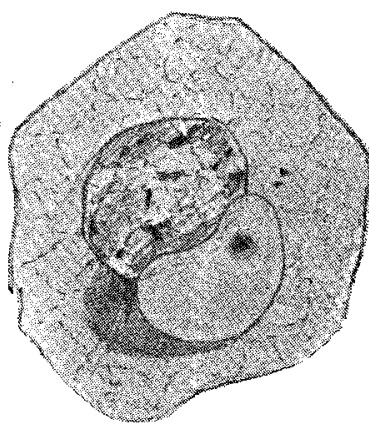

Spermatid of man (later stage). together so that at a later stage in the metamorphosis of the cell into a spermatozoon there only remains a single large clear body, bounded by a distinct membrane, containing in the centre one or more darkly staining granules (Fig. 4).

3 Greenough: Third Report of the Caroline Brewer Croft Cancer

Commission, Harvard Medical School, 1905.

Honda: Virchow's Archiv, vol. clxxiv.

5 Borrel : Annales de l'Institut Pasteur, vol. xv. This author was on the right track in attributing importance to the archoplasm, but the erroneous interpretation placed on the centrosomes precluded his arriving at a satisfactory conclusion as to the nature of the bodies under discussion.

6 Benda: Verhandlungen der Deutschen Gesellscbaft für Chirurgie, 1902.

7 Moore: Internationale Monatschrift für Anatomie und Physiologie, vol. $x i$. 